\title{
Is reduction or arthrodesis in situ the optimal choice for adolescent spondylolisthesis? - a systematic review and meta- analysis
}

\author{
Xuqiang Zhan ${ }^{1 \#}$, Xin Xi ${ }^{1 \#}$, Fuping $\mathrm{Li}^{2}$, Qingzhi Xiang ${ }^{1}$, Jikui Qian ${ }^{1}$, Haixin $\mathbf{Y u}^{1}$, Lei He ${ }^{1}$, Yan Yu ${ }^{1}$, \\ Liming Cheng ${ }^{1}$
}

${ }^{1}$ Department of Spine Surgery, Tongji Hospital, Tongji University School of Medicine, Shanghai, China; ${ }^{2}$ Department of Spine Surgery, Shanghai Fourth People's Hospital Affiliated to Tongji University School of Medicine, Shanghai, China

Contributions: (I) Conception and design: X Zhan, X Xi, Y Yu; (II) Administrative support: L Chen; (III) Provision of study materials or patients: X Zhan, X Xi; (IV) Collection and assembly of data: X Zhan, X Xi, F Li, Q Xiang; (V) Data analysis and interpretation: All authors; (VI) Manuscript writing: All authors (VII) Final approval of manuscript: All authors.

\#These authors contributed equally to this work.

Correspondence to: Yan Yu. Department of Spine Surgery, Tongji Hospital, Tongji University School of Medicine, 389 Xincun Road, Shanghai 200065, China. Email: yyu15@tongji.edu.cn.

Background: Controversy remains about the choice of reduction or arthrodesis in situ for surgical management of adolescent spondylolisthesis, while no systematic review and meta-analysis were performed to determine which one is the optimal surgical choice. The study aims to compare outcomes of the two surgical strategies for adolescent spondylolisthesis.

Methods: A comprehensive search was performed through PubMed, Web of Science, Cochrane Library, Embase, OVID/MEDLINE, CBM, CNKI, and Wanfang with a cutoff date of May $21^{\text {st }}, 2021$. Search terms included "spondylolisthesis", "in situ" and "reduction". Included studies had following characteristics: (I) participants: adolescents with spondylolisthesis. (II) Intervention: reduction following arthrodesis. (III) Control: arthrodesis in situ. (IV) Outcomes: postoperative clinical and/or radiographic results. (V) Study design: randomized controlled trial (RCT), cohort or case-control study. Data were analyzed with Review Manager 5.4, and risk of bias assessment of studies was assessed via Newcastle-Ottawa quality assessment scale (NOS).

Results: Six cohort studies were included, with NOS scores of all $\geq 6$. There were no significant differences regarding operative time $[$ mean difference $(\mathrm{MD})=152.62 ; 95 \%$ [confidence interval $(\mathrm{CI})$ ]: -54.02 to 359.26; $\left.\mathrm{I}^{2}=96 \% ; \mathrm{P}=0.15\right]$, blood loss ( $\mathrm{MD}=786.61 ; 95 \% \mathrm{CI}:-646.82$ to $\left.2,220.04 ; \mathrm{I}^{2}=90 \% ; \mathrm{P}=0.28\right)$, patient satisfaction $\left(\mathrm{MD}=1.98 ; 95 \% \mathrm{CI}: 0.72\right.$ to $\left.5.43 ; \mathrm{I}^{2}=0 \% ; \mathrm{P}=0.18\right)$, neurological complications ( $\mathrm{MD}=1.02 ; 95 \% \mathrm{CI}: 0.25$ to 4.18; $\mathrm{I}^{2}=0 \% ; \mathrm{P}=0.98$ ), or total complications ( $\mathrm{MD}=0.59 ; 95 \% \mathrm{CI}: 0.29$ to $1.19 ; \mathrm{I}^{2}=0 \% ; \mathrm{P}=0.14$ ). However, patients undergoing reduction achieved better radiographic results: fusion rate (MD =3.09; 95\% CI: 1.22 to 7.84; $\mathrm{I}^{2}=40 \% ; \mathrm{P}=0.02$ ), postoperative pseudarthrosis ( $\mathrm{MD}=0.35 ; 95 \% \mathrm{CI}: 0.15$ to $0.79 ; \mathrm{I}^{2}=24 \% ; \mathrm{P}=0.01$ ), percentage of slippage ( $M D=-20.58 ; 95 \% \mathrm{CI}:-26.32$ to $\left.-14.84 ; \mathrm{I}^{2}=0 \% ; \mathrm{P}<0.00001\right)$, and slipping angle $(\mathrm{MD}=-10.05$; 95\% CI: -14.55 to $\left.-5.54 ; \mathrm{I}^{2}=0 \% ; \mathrm{P}<0.0001\right)$. And no overt publication bias was found in the studies.

Discussion: Both reduction and arthrodesis in situ in adolescent spondylolisthesis are safe and demonstrate good clinical outcomes. However, reduction showed better radiographic results and was associated with less pseudarthrosis, better relief of disability, and improvements in self-image. In conclusion, reduction may be the optimal choice compared with arthrodesis in situ, but further verification of these findings is recommended using RCTs.

Keywords: Lumbar spondylolisthesis; adolescent; arthrodesis; reduction; in situ 
Submitted Mar 10, 2021. Accepted for publication Jun 22, 2021.

doi: 10.21037/apm-21-569

View this article at: https://dx.doi.org/10.21037/apm-21-569

\section{Introduction}

Spondylolisthesis is characterized as the anterior displacement of a vertebra on the subjacent one and has a prevalence rate of approximately $15 \%$ among patients with low back pain (1). Spondylolisthesis can be observed in different age groups, including adolescents, among which spondylolisthesis has proven to be the most common cause of low back pain. In the last decade, it has been associated with increased morbidity and a heavy economic burden $(2-5)$. In the general population, adolescents and adults show a similar incidence of $6 \%$, but athletes engaged in specific sporting activities show a much higher incidence $(23-62 \%)$, and most of these are adolescents $(6,7)$. Moreover, progression of spondylolisthesis increases with age as constant stresses are applied to the slipping vertebra-the condition progresses from an asymptomatic status to long-term pain in the lower back and extremities or an increased percentage of slippage, which can severely affect the individual's quality of life as an adult (8-11).

The management of spondylolisthesis involves conservative treatment and surgical interventions. Nonoperative management tends to be considered for minimally symptomatic or asymptomatic adolescents with low-grade spondylolisthesis (12). At the same time, surgical treatment provides a better outcome for those who are unresponsive to conservative therapy, such as individuals with high-grade spondylolisthesis, continual symptomatology, or neurological deficits (13-16). In terms of surgical management, arthrodesis has shown to be effective for lumbar spondylolisthesis (17), but consensus has yet to be reached on whether reduction or arthrodesis in situ is the more suitable technique for adolescent spondylolisthesis. The choice of surgical management for adolescents is especially important when different surgical approaches can affect prognosis. Issues such as intraoperative neurological injury, restoration of sagittal balance, and postoperative pseudarthrosis can significantly impact the adolescent's positive self-image and need for physical exercise (18). Previous studies vary greatly in their opinions. Several researchers have argued that superior postoperative results are obtained with arthrodesis in situ compared with the reduction due to reduced blood loss and a shorter operative time; that there is a higher risk of intraoperative neurologic deficits associated with reduction, and that no correlation was found between reduction and improved clinical outcomes (19-22). Opponents of these opinions have argued that arthrodesis in situ has a higher mean blood loss, a higher incidence of neurologic complications and that no statistical differences have been found in operative time or clinical outcomes between the two procedures $(23,24)$. At the same time, other authors have reported that reduction facilitates the restoration of lumbar sagittal alignment, thus indirectly creating decompression and improving the fusion rate, and has the advantages of long-term stability and a reduced risk of pseudarthrosis $(25,26)$. However, no obvious improvement in fusion rates has been reported in other studies $(23,27)$. Furthermore, many of these studies either had no comparison group or no division in ages, indicating that the results may not be applicable or relevant for adolescent spondylolisthesis.

Therefore, the purpose of this review is to compare the outcomes of the two different surgical strategies for adolescent spondylolisthesis and provide a better option for young patients. We present the following article following the PRISMA reporting checklist (available at https://dx.doi. org/10.21037/apm-21-569).

\section{Methods}

\section{Literature search strategy}

Systematic retrieval was performed by searching PubMed [1981-2021], WOS [1981-2021], Cochrane Library [2006-2021], Embase [1979-2021], OVID/MEDLINE [1981-2021], CBM [2002-2021], CNKI [1995-2021], and Wanfang [2009-2021] via the keywords "spondylolisthesis" in combination with "in situ" and "reduction", with a cutoff date of May $21^{\text {st }}, 2021$. More specifically, the search terms in the various databases are listed as follows: $((($ reset) OR (reduction)) OR (reductive)) AND (((in-situ[Title/ Abstract]) OR (in situ[Title/Abstract])) OR (original[Title/ Abstract]))) AND (("Spondylolysis"[Mesh]) OR "Spondylolisthesis"[Mesh]) in PubMed; TS = (spondylos?s or sponylolys?s or spondylolisthes?s or spondylisthes?s) 


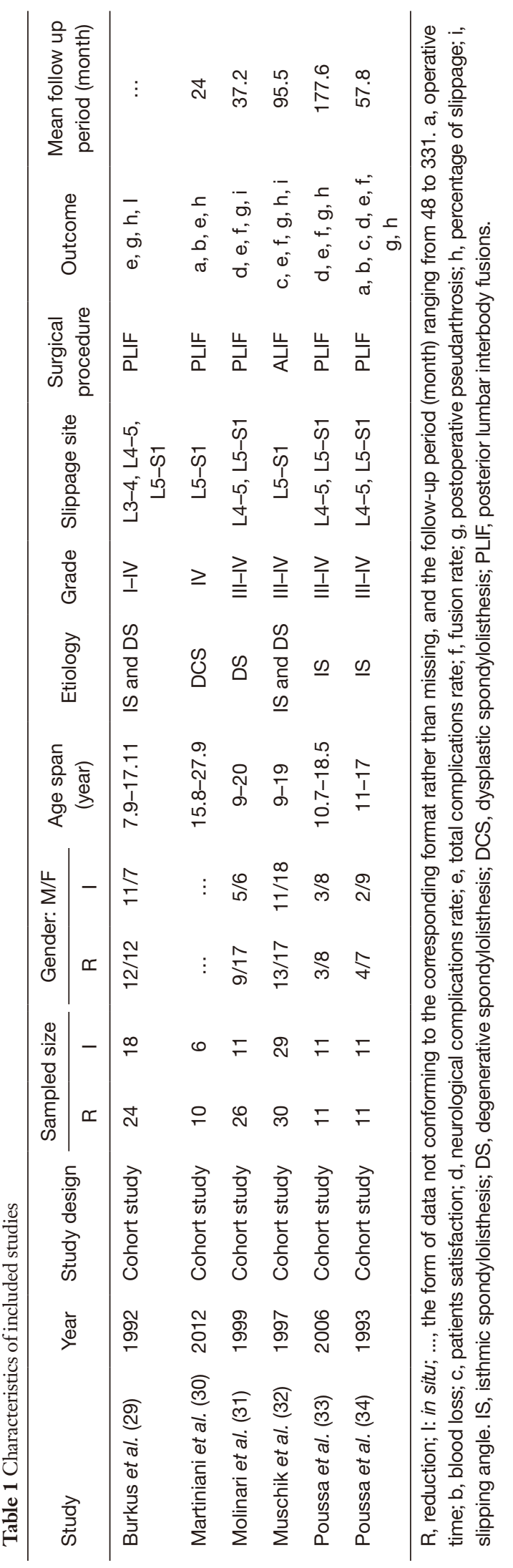

AND TS=(in situ, or in-situ, or original) AND $\mathrm{TS}=($ reduction, or reductive, or reset) in Web of Science; $\mathrm{TKA}=$ ('spondylolisthesis') AND TKA=('arthrodesis in situ' + 'reduction') in CNKI. Moreover, we checked the references of all original relevant trials and reviews for other supplementary articles.

\section{Study eligibility criteria}

Studies were included based on the following criteria: (I) subjects with a preoperative diagnosis of lumbar spondylolisthesis; (II) the surgical treatment was a comparison of fusion in situ with reduction; (III) the study design was either randomized controlled trials (RCTs), cohort, or case-control; (IV) the study included adolescent patients aged 10-24 years (28); (V) all included patients were followed up for at least 24 months postoperatively.

The exclusion criteria were as follows: (I) reviews, case reports, letters to the editors, conference abstracts, and editorials; (II) articles not specifically reporting outcomes, and data overlapping with previous publications.

All the processes were performed independently by two reviewers. When faced with disagreement, the reviewers reached a consensus by group discussion.

\section{Data extraction}

Relevant data were extracted independently by the two reviewers, who e-mailed the authors when necessary for specific information not included in their articles. Moreover, disagreements between the two reviewers were resolved by group discussion. The information collected fell into two categories: basic information concerning the trials and patients, and clinical and radiological outcomes. More specifically, the surname of the primary author, year of publication, study design, the number and age span of participants, gender, etiology, grade of spondylolisthesis, site of slippage, type of surgery, and mean follow up period can be found in Table 1. Clinical and radiographic results concerning operative time, blood loss, patient satisfaction, neurological complications, total complications, fusion rate, postoperative pseudarthrosis, percentage of slippage, and slipping angle can also be found in Table 1 .

\section{Assessment of methodological quality}

The Newcastle-Ottawa quality assessment scale (NOS) (35) was adopted for the six cohort studies. As described above, 


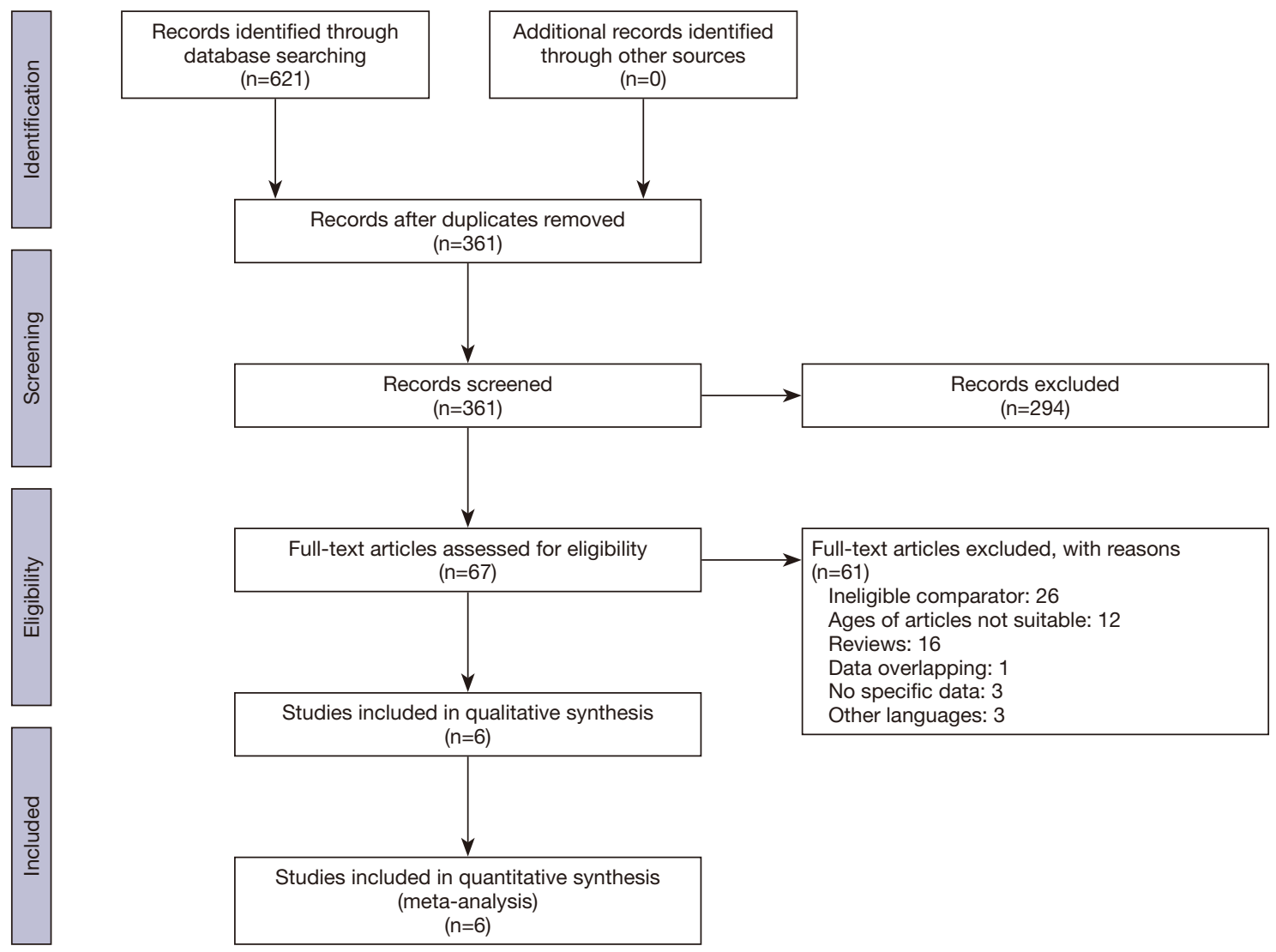

Figure 1 The screening flow diagram of the included studies.

two reviewers performed the assessment independently, and any disagreement was resolved by group discussion.

\section{Statistical analysis}

Data were analyzed with Review Manager 5.4. Continuous variables in each treatment group are reported as the mean, standard deviation (SD), and a total number of patients to obtain the pooled mean difference (MD) and the $95 \%$ confidence interval (CI). Dichotomous outcomes are presented as odds ratio (OR) with $95 \%$ CI by the number of events and the total patients in each treatment arm. Heterogeneity among studies was analyzed with Cochrane's $\mathrm{Q}$ test and the $\mathrm{I}^{2}$ statistic. Heterogeneity was taken into account if $\mathrm{P} \leq 0.1$ and/or $\mathrm{I}^{2}>50 \%$ were observed. Namely, a random-effects model was adopted in the case of $\mathrm{P} \leq 0.1$ and/or $\mathrm{I}^{2}>50 \%$, otherwise a fixed-effects model was used. A funnel plot was used for the main and most frequently reported outcome to screen for potential publication bias, and all studies were symmetrically distributed and within $95 \%$ CI, which indicate no publication bias.

\section{Results}

\section{Search results}

As shown in Figure 1, a total of 621 records were found by the database searches. After removing 260 studies for duplication and excluding 294 others based on titles and abstracts, the remaining 67 records were examined, and a further 61 studies were excluded for the following reasons: twenty-six articles did not contain comparisons of reduction and in-situ procedures, 12 articles did not include the required age ranges, 16 were reviews, one had overlapping data, three were lacking specific data, and three were in languages other than English or Chinese. Finally, six English language studies (29-34) with a total of 198 patients were included in the qualitative and quantitative analyses. 
Table 2 Risk of bias assessment of cohort studies (NOS*)

\begin{tabular}{|c|c|c|c|c|c|c|}
\hline Criteria & $\begin{array}{l}\text { Burkus et al., } \\
1992\end{array}$ & $\begin{array}{l}\text { Martiniani et al., } \\
2012\end{array}$ & $\begin{array}{l}\text { Molinari et al., } \\
1999\end{array}$ & $\begin{array}{l}\text { Muschik et al., } \\
1997\end{array}$ & $\begin{array}{l}\text { Poussa et al., } \\
2006\end{array}$ & $\begin{array}{c}\text { Poussa et al., } \\
1993\end{array}$ \\
\hline \multicolumn{7}{|l|}{ Selection } \\
\hline Selection of the non-exposed cohort & 1 & 1 & 0 & 1 & 1 & 1 \\
\hline $\begin{array}{l}\text { Demonstration that outcome of interest } \\
\text { was not present at start of study }\end{array}$ & 1 & 1 & 1 & 1 & 1 & 1 \\
\hline \multicolumn{7}{|l|}{ Comparability } \\
\hline $\begin{array}{l}\text { Comparability of cohorts on the basis of } \\
\text { the design or analysis }\end{array}$ & 1 & 1 & 0 & 1 & 1 & 1 \\
\hline $\begin{array}{l}\text { Was follow-up long enough for outcomes } \\
\text { to occur }\end{array}$ & 1 & 1 & 1 & 1 & 1 & 1 \\
\hline Adequacy of follow up of cohorts & 1 & 1 & 1 & 1 & 1 & 1 \\
\hline Total score & 8 & 8 & 6 & 8 & 7 & 8 \\
\hline
\end{tabular}

*, NOS, Newcastle-Ottawa quality assessment scale.

\section{Description of included studies}

As shown in Table 1, the included research papers were all cohort studies. Among the 198 patients, 112 had received reduction following arthrodesis, and the remaining 86 individuals underwent arthrodesis in situ. Except for five patients with 1 or 2 years younger or older than the age criterion, 193 patients ranged in age from 10 to 24 years. In terms of the etiology of spondylolisthesis, one study comprised dysplastic spondylolisthesis and the remainder comprised isthmic and degenerative spondylolisthesis. The grades of spondylolisthesis were either Grade IV or Grade III-IV, with five studies reporting on high grade spondylolisthesis, and one containing patients with mixed grades. Most of the surgical interventions were posterior lumbar interbody fusions (PLIF), with one study of anterior lumbar interbody fusion (ALIF). The mean follow-up period varied from 24 months to 177.6 months, with all patients followed up for at least 24 months postoperatively [the follow-up period of one study (29) ranged from 48 to 331 months]. The comparative items among studies are listed below the outcomes in Table 1 .

\section{The methodological quality of included studies}

The methodological quality of the eligible studies was evaluated by the NOS (Table 2). Any disagreements between the two reviewers were settled by group discussion until consensus was reached.

\section{Clinical results}

\section{Operative time}

Operative time was reported in two studies, as shown in Figure 2. A random-effects model was used due to substantial heterogeneity in the pooled results $\left(\mathrm{I}^{2}=96 \%\right)$. Results demonstrated no significant difference between the reduction and in situ groups ( $\mathrm{MD}=152.62 ; 95 \% \mathrm{CI}:-54.02$ to $359.26 ; \mathrm{P}=0.15$ ).

\section{Blood loss}

Two studies covered the comparison of blood loss between the reduction and in situ groups. As seen in Figure 3, a random-effects model was used due to obvious heterogeneity $\left(I^{2}=90 \%\right)$. No significant difference between 


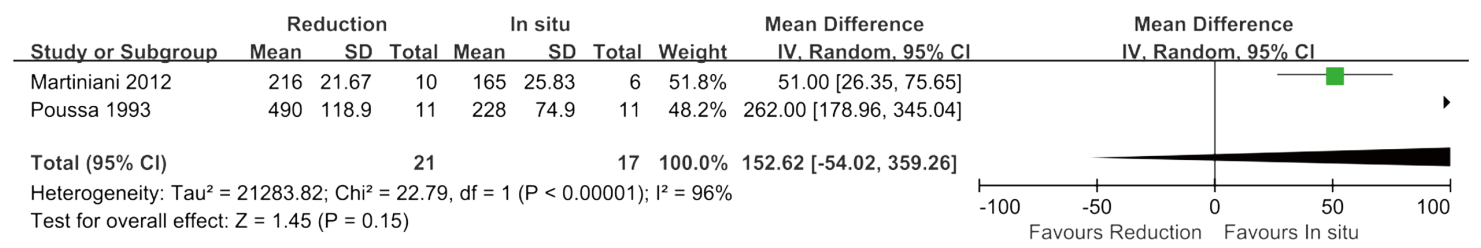

Figure 2 Analysis of operative time (min) between reduction and in situ.

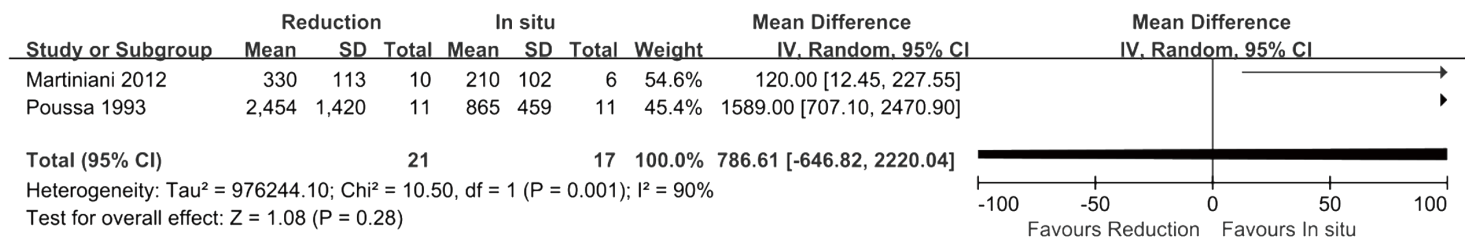

Figure 3 Analysis of blood loss (mL) between reduction and in situ.

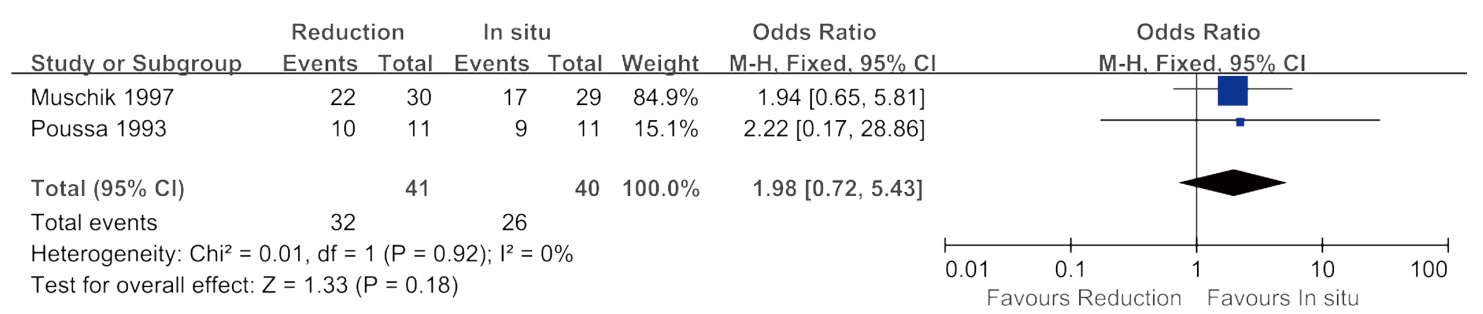

Figure 4 Analysis of satisfaction between reduction and in situ.

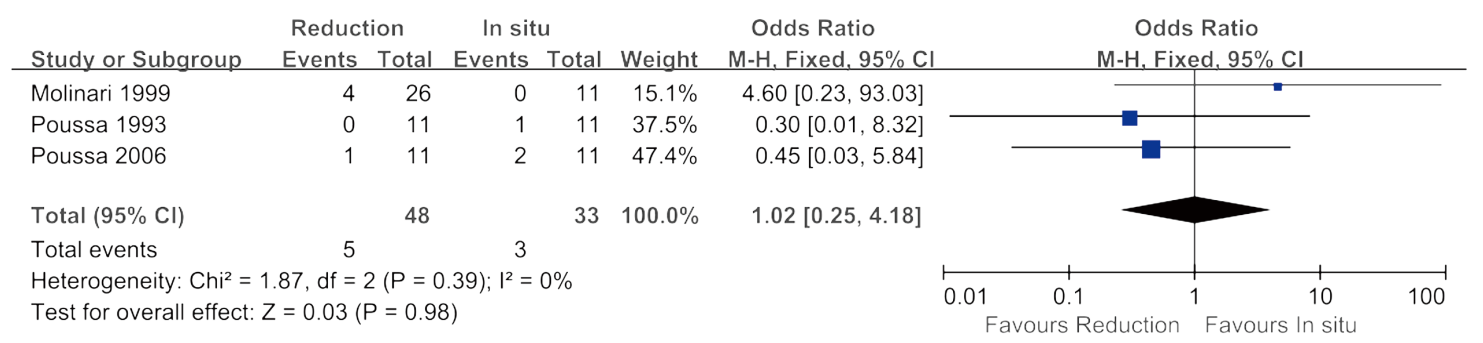

Figure 5 Analysis of neurological complications between reduction and in situ.

the reduction and in situ groups was observed $(\mathrm{MD}=786.61$;

95\% CI: -646.82 to $2,220.04 ; \mathrm{P}=0.28)$.

\section{Patient satisfaction}

As shown in Figure 4, two studies compared patient satisfaction in the reduction and in situ groups, and a fixedeffects model was applied because of nil heterogeneity $\left(\mathrm{I}^{2}=0 \%\right)$. No significant difference between the reduction and in situ groups was observed (MD =1.98; 95\% CI: 0.72 to $5.43 ; \mathrm{P}=0.18)$.

\section{Neurological complications}

As shown in Figure 5, three studies compared neurological complications in the reduction and in situ groups. A fixedeffects model was adopted because of low heterogeneity $\left(\mathrm{I}^{2}=0 \%\right)$. No significant difference between the reduction and in situ groups was observed (MD =1.02; 95\% CI: 0.25 to $4.18 ; \mathrm{P}=0.98)$. 


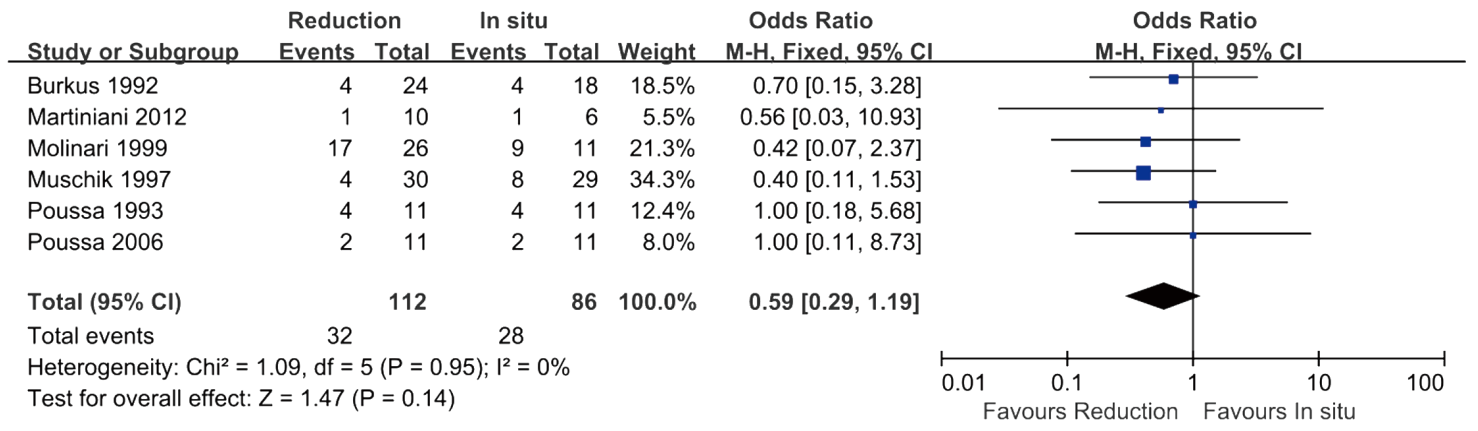

Figure 6 Analysis of total complications between reduction and in situ.

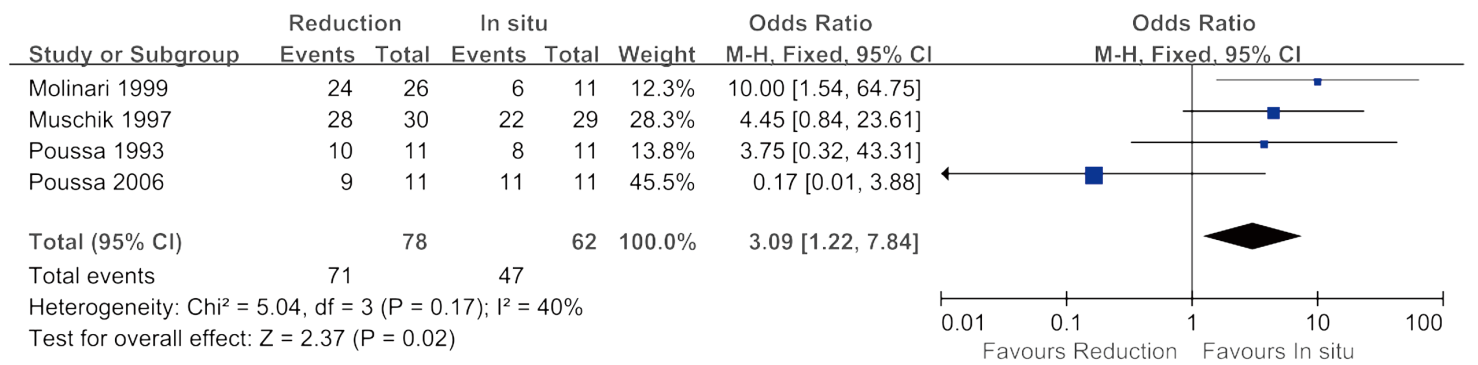

Figure 7 Analysis of fusion rate between reduction and $i n$ situ.

\section{Total complications}

Data concerning total complications were extracted from all six studies (Figure 6). A fixed-effects model was used owing to the low heterogeneity of the merged results $(=0 \%)$. No significant difference between the reduction and in situ groups was observed (MD $=0.59 ; 95 \% \mathrm{CI}: 0.29$ to $1.19 ; \mathrm{P}=0.14$ ).

\section{Radiographic results}

\section{Fusion rate}

The fusion rate was reported in four studies, as shown in Figure 7. Because there was no obvious heterogeneity in the pooled results $\left(I^{2}=40 \%\right)$, a fixed-effects model was used. The in situ group had significantly fewer fusions than the reduction group ( $\mathrm{MD}=3.09 ; 95 \% \mathrm{CI}: 1.22$ to $7.84 ; \mathrm{P}=0.02$ ).

\section{Postoperative pseudarthrosis}

Five studies reported on differences in the incidence of postoperative pseudarthrosis between the reduction and in situ groups. A fixed-effects model was applied due to low heterogeneity $\left(\mathrm{I}^{2}=24 \%\right)$. As shown in Figure 8, the reduction was associated with significantly less postoperative pseudarthrosis compared with the in situ procedure (MD $=0.35 ; 95 \%$ CI: 0.15 to $0.79 ; \mathrm{P}=0.01$ ).

\section{Percentage of slippage}

Five studies reported the percentage of slippage. Figure 9 shows the results of a random-effects model conducted due to large heterogeneity $\left(\mathrm{I}^{2}=78 \%\right)$. The percentage of slippage in the reduction group demonstrated a significantly better outcome than that of the in situ group $(M D=-26.31 ; 95 \% \mathrm{CI}:-38.16$ to $-14.46 ; \mathrm{P}<0.0001)$. Figure 10 shows the result with low heterogeneity $\left(\mathrm{I}^{2}=0 \%\right)$ after performing sensitivity analysis and removing the study conducted by Martiniani et al. (30) (MD =-20.58; 95\% CI: -26.32 to $-14.84 ; \mathrm{P}<0.00001)$.

\section{Slipping angle}

Data from three studies were used to compare the slipping angle at follow-up, as shown in Figure 11. A fixed-effects model was used due to low heterogeneity in the pooled results $\left(\mathrm{I}^{2}=0 \%\right)$. The results showed that the slipping angle in the reduction group was significantly less than that in the in situ group (MD $=-10.05$; 95\% CI: -14.55 to -5.54 ; $\mathrm{P}<0.0001)$. 


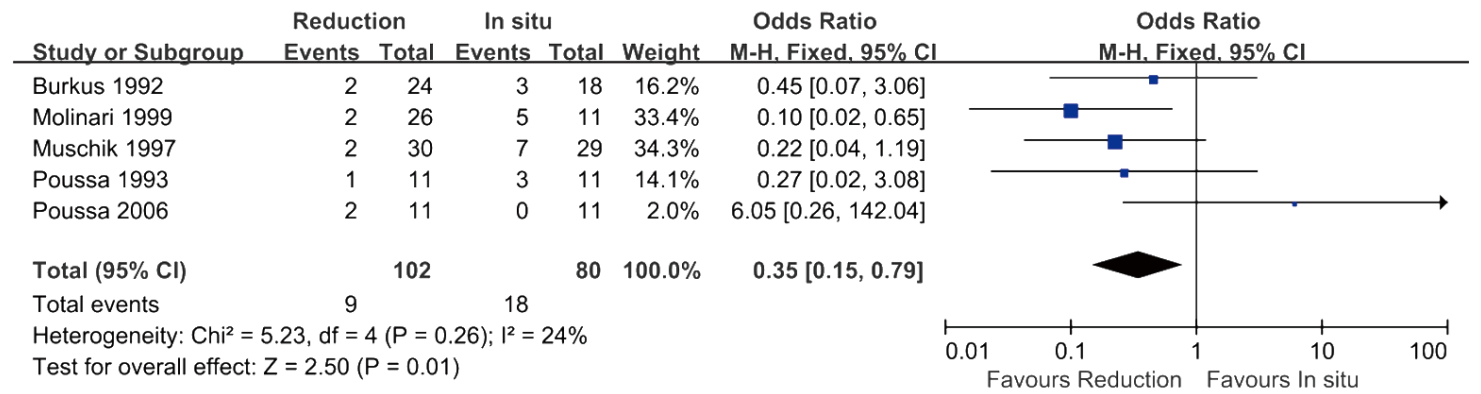

Figure 8 Analysis of postoperative pseudarthrosis between reduction and in situ.

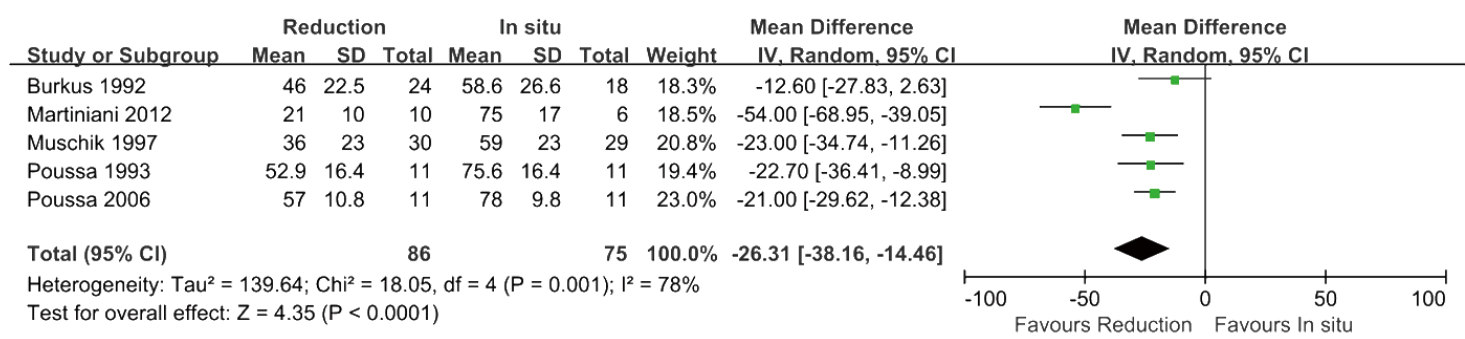

Figure 9 Analysis of percentage of slippage between reduction and in situ.

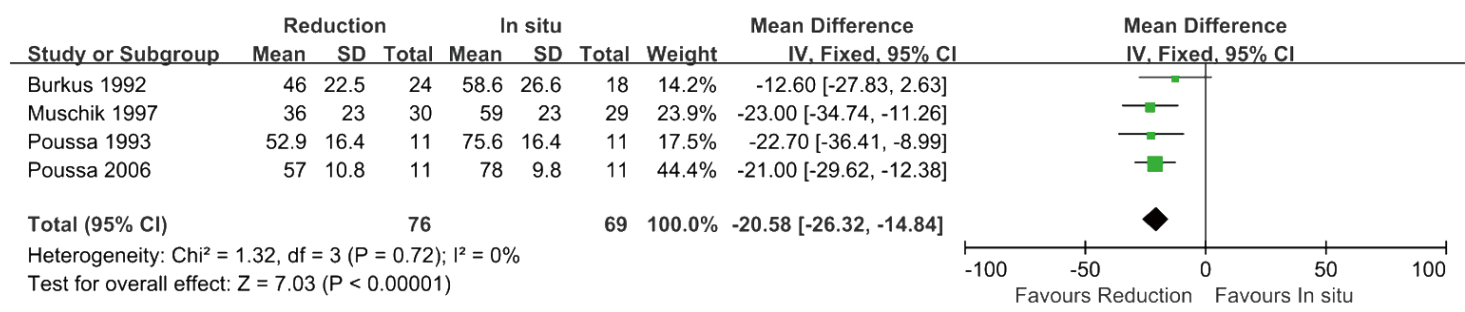

Figure 10 Analysis of percentage of slippage between reduction and in situ after removing Martiniani et al. 2012.

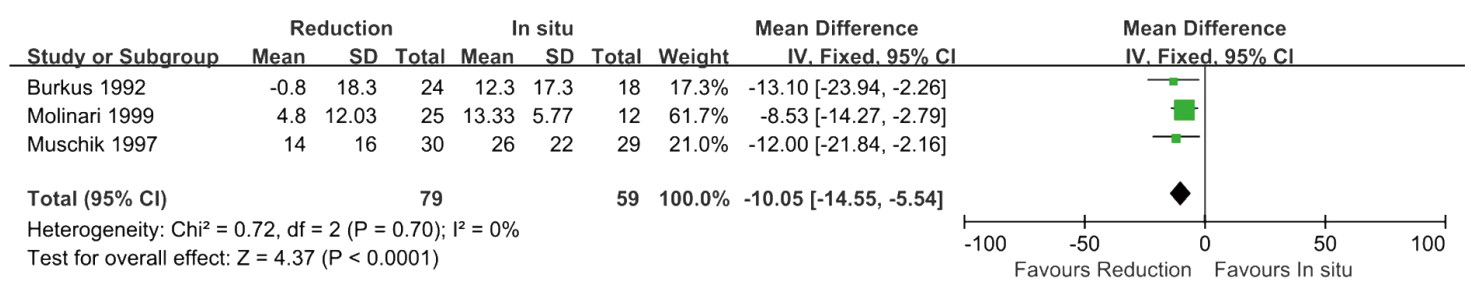

Figure 11 Analysis of slipping angle between reduction and in situ.

\section{Publication bias}

As shown in Figure 12, publication bias was assessed by a funnel plot, describing the total complications rates between the two groups. All six studies lay inside the $95 \%$ CI and the distribution was nearly symmetrical, indicating that there was no overt publication bias in the meta-analysis.

\section{Discussion}

Debate continues concerning whether reduction or 


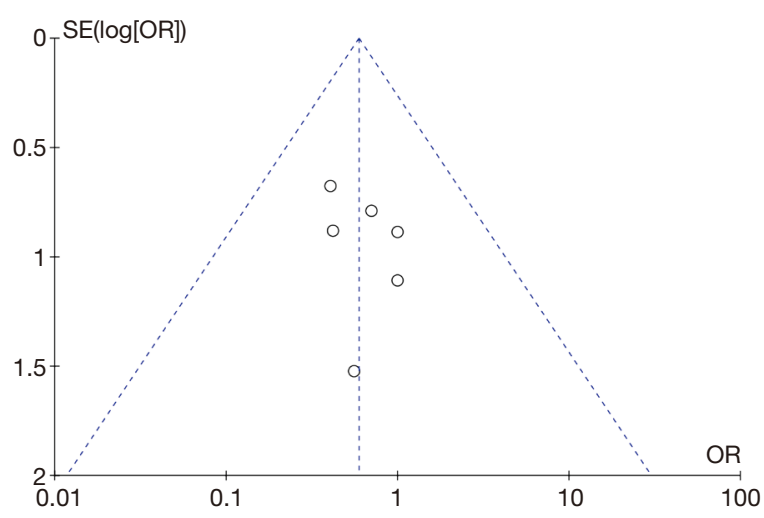

Figure 12 The assessment of publication bias through funnel plot illustrated by total complications rate.

arthrodesis in situ is the better surgical procedure for adolescent spondylolisthesis (29-34). Transfeldt and Mehbod (36) conducted a comparison of the two surgical interventions in high grade spondylolisthesis in a pediatric population, but their study did not include a quantitative analysis, difficult to draw an accurate conclusion. We conducted a meta-analysis, including a more recent study (30), to compare the outcomes between the two surgical procedures.

Six studies were taken into consideration in this review; however, they were cohort studies rather than RCTs. Concerning assessing the quality of the included studies, the research by Molinari et al. 1999 (31) received only 6 points because most patients in the reduction group had undergone prior surgery, unlike the control group, which implied a selection bias in participants. Despite this, the NOS scores of all studies were $\geq 6$, indicating that they were generally of high quality. We also considered the heterogeneity of the included studies. Substantial heterogeneity was found in operative time and blood loss results, which can probably be attributed to the recent advancement in surgical techniques-arthrodesis surgery nowadays causes less blood loss and needs less operative time than in the past. A high degree of heterogeneity was also found in comparisons of the percentage of slippage, but low heterogeneity was obtained by removing the Martiniani et al. study (30) in the sensitivity analysis; the greater reduction in this percentage of slippage study may account for this phenomenon.

An evaluation of clinical safety was conducted by comparing clinical outcomes, except for patient satisfaction, of the reduction and arthrodesis in situ procedures. Previous studies have indicated that a longer operative time and greater blood loss are associated with a higher incidence of intraoperative and postoperative complications (37-40). However, thanks to the recent advances in surgical instrumentation and technology, acceptable safety limits for operative time and amount of blood loss have been achieved $(23,41,42)$, which can also be seen in the decrease in the operative time and blood loss according to the results of Poussa 1993 and Martiniani 2012 in Figures 1 and 2. Moreover, in contrast to the previous opinions that longer operative times and greater blood loss occurred with reduction, we found no significant differences between reduction and in situ group in the case of operative time $(\mathrm{P}=0.15)$ and blood loss $(\mathrm{P}=0.28)$. It has also been reported that risk of neurological injury was higher in patients receiving reduction $v s$. arthrodesis in situ procedure $(10.0 \%$ vs. $2.1 \%, \mathrm{P}<0.05)(21)$. However, in our study, similar rates of neurological deficits was reported in both the reduction and in-situ group $(10.4 \%$ vs. $9.1 \%, \mathrm{P}=0.98)$, and also for total complications ( $28.6 \%$ vs. $32.6 \%, \mathrm{P}=0.14)$.

Given that arthrodesis in situ for adolescent spondylolisthesis has been proven clinically safe in a previous study (24), and that no statistically significant differences in operative time, blood loss, or complications between the two groups were found in our results, we conclude that reduction for adolescent spondylolisthesis is also a clinically safe procedure. As for the effectiveness of the two treatments, several studies reported positive results of functional tests and significant improvement in pain relief in both groups, and both of these outcomes are essential for adolescents who have high requirements for spinal motor function $(30,31,33,34)$. The high postoperative patient satisfaction demonstrated the effectiveness of the reduction and in situ group $(78.0 \%$ vs. $65.0 \%, \mathrm{P}=0.18)$. In general, the postoperative clinical outcomes in the reduction group were as high as those in the in situ group, indicating that the two approaches are both safe and effective in terms of clinical outcomes.

Significant differences were found in the radiographic results. Overall, better outcomes were observed in the reduction than in situ group-a higher fusion rate $(91.0 \%$ vs. $75.8 \%, \mathrm{P}<0.05)$, less postoperative pseudarthrosis $(8.8 \%$ vs. $22.5 \%, \mathrm{P}<0.05)$, less percentage of slippage $(\mathrm{P}<0.05)$, and less slipping angle $(\mathrm{P}<0.05)$. A higher fusion rate brought about by reducing slipping vertebra is associated with less shear force on the implants across the disc space and more contact area between the implants and the endplates, therefore avoiding future instability and complications $(43,44)$. A previous study has shown that increased shear 
stress at the disc is correlated with an increased percentage of slippage, and shear stress combined with other stresses, especially in the lumbosacral junction, aggravated the slippage of the L5 vertebra by inducing the formation of a sacral dome (45). Though immediate stability can be achieved by instrumentation in arthrodesis in situ, achieving long-term stability is more challenging in this techniquethe internal fixation materials may break down or become damaged after continual stress and fatigue. Long-term stability would therefore depend on subsequent fusion $(46,47)$. There are significant implications for adolescents following a low fusion rate, one of which is postoperative pseudarthrosis. Pseudarthrosis, as one of the most common complications of lumbar spinal surgery, usually leads to recurrent postoperative pain and disability and even to revision lumbar surgery $(48,49)$. The prognosis after a revision surgery is not as favorable as after the first operation: one study reported that although non-union was corrected, $10 \%$ of patients reported no change in their overall wellbeing, 26\% stated that they were worse, and the overall well-being status after the revision was generally worse than before (49). Sometimes, pseudarthrosis can be adjusted by revision surgery; nevertheless, the mental health symptoms secondary to pseudarthrosis-associated back pain may be more refractory (50). For adolescents at a critical stage of mental development, the negative emotions they experience may become a danger to their future healthy functioning. Equally important are the percentage of slippage and the slipping angle. A large percentage of slippage has been associated with a high slipping angle with the resultant appearance of significant lumbosacral kyphosis, thus leading to an anomalous spinal alignment and disturbance of the sagittal spinopelvic balance (51-53).

In turn, sagittal spinopelvic imbalance might influence the pathogenesis of spondylolisthesis (53). Meanwhile, anomalous spinal alignment and an unbalanced sagittal spinopelvic system remain problematic for patients who have received arthrodesis in situ, leaving them with abnormal spinal mechanics and a diminished selfimage. Large lumbosacral kyphosis creates maximal hyperextension of the thoracolumbar region for the sake of sagittal balance, causing muscle fatigue, disc degeneration, and changes of facet. Previous studies have also shown that some moderate, but recurring, low back and thigh pain after arthrodesis in situ results from terminal degeneration (54,55). A new classification of spondylolisthesis based on spinopelvic posture suggests that reduction should be applied in cases of high-grade spondylolisthesis with a retroverted pelvis (56) because further slippage or progression of lumbosacral deformity after arthrodesis in situ could occur in patients with highgrade spondylolisthesis with a balanced spine, which may result in a retroverted pelvis, unbalanced spine, and residual pain in the future (57). Because high-grade spondylolisthesis is very common among adolescent isthmic spondylolisthesis, progression of slippage and the resultant sagittal imbalance would not be a good outcome for these patients after arthrodesis in situ (18).

In contrast, adolescents in the reduction group showed less evidence of late progression of lumbosacral deformity (29). Self-image is vitally important for adolescents, especially for those with abnormal physical presentations (58). For these patients, full reduction of spondylolisthesis deformity meant correcting the abnormal waddling gait, restoration of trunk height, and disappearance of protruding ribs and flattened buttocks (59). Sometimes, the only reason for the reduction was that they hoped to improve their appearance (60).

The major shortcoming of this meta-analysis is that a total of five patients were 1 or 2 years younger or older than the criterion for adolescent age, which may weaken the accuracy of the findings. In addition, the lack of RCTs for adolescent spondylolisthesis and the small sample size should be taken into account. Another limitation is the few comparative items both in clinical and radiographic parameters due to the difficulty in obtaining the raw data. Furthermore, only Chinese and English databases were checked, so articles published in other languages may have been missed. Finally, we failed to analyze lumbar spondylolisthesis by subgroups based on etiology due to the small number of included studies.

In conclusion, both reduction and arthrodesis in situ of adolescent spondylolisthesis are safe and have good clinical outcomes. Reduction demonstrated better results concerning radiographic outcomes and was associated with less chance of pseudarthrosis, better relief of disability, and improvement of self-image. In conclusion, reduction may be the optimal choice compared with arthrodesis in situ for the surgical management of adolescent spondylolisthesis, but further verification of these findings is recommended using RCTs.

\section{Acknowledgments}

We would like to thank D. Fitzgerald and J. Chapnick for their help in polishing our paper. 
Funding: This work was supported by research grants from the National Natural Science Foundation of China (No. 81873774), the Shanghai Rising-Star Program (No. 18QA 1403800), and the Shanghai Excellent Young Medical Talents Training Program (No. 2018YQ22), Shanghai Municipal Health Commission Program (No. 201940244).

\section{Footnote}

Reporting Checklist: The authors have completed the PRISMA reporting checklist. Available at https://dx.doi. org/10.21037/apm-21-569

Conflicts of Interest: All authors have completed the ICMJE uniform disclosure form (available at https://dx.doi. org/10.21037/apm-21-569). The authors have no conflicts of interest to declare.

Ethical Statement: The authors are accountable for all aspects of the work in ensuring that questions related to the accuracy or integrity of any part of the work are appropriately investigated and resolved.

Open Access Statement: This is an Open Access article distributed in accordance with the Creative Commons Attribution-NonCommercial-NoDerivs 4.0 International License (CC BY-NC-ND 4.0), which permits the noncommercial replication and distribution of the article with the strict proviso that no changes or edits are made and the original work is properly cited (including links to both the formal publication through the relevant DOI and the license). See: https://creativecommons.org/licenses/by-nc-nd/4.0/.

\section{References}

1. Ishimoto Y, Yoshimura N, Muraki S, et al. Association of Lumbar Spondylolisthesis With Low Back Pain and Symptomatic Lumbar Spinal Stenosis in a Populationbased Cohort: The Wakayama Spine Study. Spine (Phila Pa 1976) 2017;42:E666-71.

2. Turner PG, Green JH, Galasko CS. Back pain in childhood. Spine (Phila Pa 1976) 1989;14:812-4.

3. King HA. Back pain in children. Orthop Clin North Am 1999;30:467-74, ix.

4. Parker SL, McGirt MJ. Determination of the minimum improvement in pain, disability, and health state associated with cost-effectiveness: introduction of the concept of minimum cost-effective difference. Neurosurgery
2012;71:1149-55.

5. Horn SR, Shepard N, Poorman GW, et al. National Trends in the Prevalence, Treatment, and Associated Spinal Diagnoses Among Pediatric Spondylolysis Patients. Bull Hosp Jt Dis (2013) 2018;76:246-51.

6. LAURENT LE, EINOLA S. Spondylolisthesis in children and adolescents. Acta Orthop Scand 1961;31:45-64.

7. Harvey CJ, Richenberg JL, Saifuddin A, et al. The radiological investigation of lumbar spondylolysis. Clin Radiol 1998;53:723-8.

8. Lonstein JE. Spondylolisthesis in children. Cause, natural history, and management. Spine (Phila $\mathrm{Pa}$ 1976) 1999;24:2640-8.

9. Logroscino G, Mazza O, Aulisa G, et al. Spondylolysis and spondylolisthesis in the pediatric and adolescent population. Childs Nerv Syst 2001;17:644-55.

10. Wimberly RL, Lauerman WC. Spondylolisthesis in the athlete. Clin Sports Med 2002;21:133-45, vii-viii.

11. Foreman P, Griessenauer CJ, Watanabe K, et al. L5 spondylolysis/spondylolisthesis: a comprehensive review with an anatomic focus. Childs Nerv Syst 2013;29:209-16.

12. Lundine KM, Lewis SJ, Al-Aubaidi Z, et al. Patient outcomes in the operative and nonoperative management of high-grade spondylolisthesis in children. J Pediatr Orthop 2014;34:483-9.

13. Cheung EV, Herman MJ, Cavalier R, et al. Spondylolysis and spondylolisthesis in children and adolescents:

II. Surgical management. J Am Acad Orthop Surg 2006;14:488-98.

14. Alhammoud A, Schroeder G, Aldahamsheh O, et al. Functional and Radiological Outcomes of Combined Anterior-Posterior Approach Versus Posterior Alone in Management of Isthmic Spondylolisthesis. A Systematic Review and Meta-Analysis. Int J Spine Surg 2019;13:230-8.

15. Kalani MA, Kouloumberis P, Richards AE, et al.

Retrospective radiographic analysis of anterior lumbar fusion for high grade lumbar spondylolisthesis. J Spine Surg 2020;6:650-8.

16. Cavalier R, Herman MJ, Cheung EV, et al. Spondylolysis and spondylolisthesis in children and adolescents: I. Diagnosis, natural history, and nonsurgical management. J Am Acad Orthop Surg 2006;14:417-24.

17. Zhou SG, Liu CH, Dai KH, et al. Lumbar Fusion for Spondylolisthesis: A Bayesian Network Metaanalysis of Randomized Controlled Trials. Clin Spine Surg 2020. [Epub ahead of print]. doi: 10.1097/ BSD.0000000000001094.

18. Beck AW, Simpson AK. High-Grade Lumbar 
Spondylolisthesis. Neurosurg Clin N Am 2019;30:291-8.

19. Ogilvie JW. Complications in spondylolisthesis surgery. Spine (Phila Pa 1976) 2005;30:S97-101.

20. Gong K, Wang Z, Luo Z. Reduction and transforaminal lumbar interbody fusion with posterior fixation versus transsacral cage fusion in situ with posterior fixation in the treatment of Grade 2 adult isthmic spondylolisthesis in the lumbosacral spine. J Neurosurg Spine 2010;13:394-400.

21. Fu KM, Smith JS, Polly DW Jr, et al. Morbidity and mortality in the surgical treatment of six hundred five pediatric patients with isthmic or dysplastic spondylolisthesis. Spine (Phila Pa 1976) 2011;36:308-12.

22. Maciejczak A, Jabłońska-Sudoł K. Correlation between correction of pelvic balance and clinical outcomes in midand low-grade adult isthmic spondylolisthesis. Eur Spine J 2017;26:3112-21.

23. Bai X, Chen J, Liu L, et al. Is reduction better than arthrodesis in situ in surgical management of low-grade spondylolisthesis? A system review and meta analysis. Eur Spine J 2017;26:606-18.

24. Lak AM, Abunimer AM, Devi S, et al. Reduction versus In Situ Fusion for Adult High-Grade Spondylolisthesis: A Systematic Review and Meta-Analysis. World Neurosurg 2020;138:512-520.e2.

25. Boos N, Marchesi D, Aebi M. Treatment of spondylolysis and spondylolisthesis with Cotrel-Dubousset instrumentation: a preliminary report. J Spinal Disord 1991;4:472-9.

26. Jiang G, Ye C, Luo J, et al. Which is the optimum surgical strategy for spondylolisthesis: Reduction or fusion in situ? A meta-analysis from 12 comparative studies. Int J Surg 2017;42:128-37.

27. Si W, Xie W, Feng C, et al. Surgical management of spondylolisthesis----intentional reduction or in situ fusion: a meta-analysis. Int J Clin Exp Med 2019;12:9642-58.

28. Sawyer SM, Azzopardi PS, Wickremarathne D, et al. The age of adolescence. Lancet Child Adolesc Health 2018;2:223-8.

29. Burkus JK, Lonstein JE, Winter RB, et al. Longterm evaluation of adolescents treated operatively for spondylolisthesis. A comparison of in situ arthrodesis only with in situ arthrodesis and reduction followed by immobilization in a cast. J Bone Joint Surg Am 1992;74:693-704.

30. Martiniani M, Lamartina C, Specchia N. "In situ" fusion or reduction in high-grade high dysplastic developmental spondylolisthesis (HDSS). Eur Spine J 2012;21 Suppl $1:$ S134-40.
31. Molinari RW, Bridwell KH, Lenke LG, et al. Complications in the surgical treatment of pediatric highgrade, isthmic dysplastic spondylolisthesis. A comparison of three surgical approaches. Spine (Phila Pa 1976) 1999;24:1701-11.

32. Muschik M, Zippel H, Perka C. Surgical management of severe spondylolisthesis in children and adolescents. Anterior fusion in situ versus anterior spondylodesis with posterior transpedicular instrumentation and reduction. Spine (Phila Pa 1976) 1997;22:2036-42; discussion 2043.

33. Poussa M, Remes V, Lamberg T, et al. Treatment of severe spondylolisthesis in adolescence with reduction or fusion in situ: long-term clinical, radiologic, and functional outcome. Spine (Phila Pa 1976) 2006;31:58390; discussion 591-2.

34. Poussa M, Schlenzka D, Seitsalo S, et al. Surgical treatment of severe isthmic spondylolisthesis in adolescents. Reduction or fusion in situ. Spine (Phila Pa 1976) 1993;18:894-901.

35. Stang A. Critical evaluation of the Newcastle-Ottawa scale for the assessment of the quality of nonrandomized studies in meta-analyses. Eur J Epidemiol 2010;25:603-5.

36. Transfeldt EE, Mehbod AA. Evidence-based medicine analysis of isthmic spondylolisthesis treatment including reduction versus fusion in situ for high-grade slips. Spine (Phila Pa 1976) 2007;32:S126-9.

37. Akins PT, Harris J, Alvarez JL, et al. Risk Factors Associated With 30-day Readmissions After Instrumented Spine Surgery in 14,939 Patients: 30-day readmissions after instrumented spine surgery. Spine (Phila Pa 1976) 2015;40:1022-32.

38. Cheng H, Chen BP, Soleas IM, et al. Prolonged Operative Duration Increases Risk of Surgical Site Infections: A Systematic Review. Surg Infect (Larchmt) 2017;18:722-35.

39. Kilic ET, Tastan NO, Sarikaya C, et al. The Application of an Enhanced Recovery After Surgery to Spine Instrumentation. Turk Neurosurg 2020;30:707-13.

40. Kla KM, Lee LA. Perioperative visual loss. Best Pract Res Clin Anaesthesiol 2016;30:69-77.

41. Ren C, Qin R, Sun P, et al. Effectiveness and safety of unilateral pedicle screw fixation in transforaminal lumbar interbody fusion (TLIF): a systematic review and metaanalysis. Arch Orthop Trauma Surg 2017;137:441-50.

42. Yavin D, Casha S, Wiebe S, et al. Lumbar Fusion for Degenerative Disease: A Systematic Review and MetaAnalysis. Neurosurgery 2017;80:701-15.

43. Guo Z, Chen Z, Qi Q, et al. The treatment of severe lumbar dysplastic spondylolisthesis. Zhonghua Wai Ke Za 
Zhi 2014;52:845-50.

44. Schoenleber SJ, Shufflebarger HL, Shah SA. The Assessment and Treatment of High-Grade Lumbosacral Spondylolisthesis and Spondyloptosis in Children and Young Adults. JBJS Rev 2015;3:01874474-201512000-00006.

45. Sevrain A, Aubin CE, Gharbi H, et al. Biomechanical evaluation of predictive parameters of progression in adolescent isthmic spondylolisthesis: a computer modeling and simulation study. Scoliosis 2012;7:2.

46. Maciejczak A, Radek A. Lumbar interbody fusion. Biomechanical significance for the spine. Neurol Neurochir Pol 1998;32:1247-59.

47. Takahashi T, Hanakita J, Ohtake Y, et al. Current Status of Lumbar Interbody Fusion for Degenerative Spondylolisthesis. Neurol Med Chir (Tokyo) 2016;56:476-84.

48. Martin BI, Mirza SK, Comstock BA, et al. Reoperation rates following lumbar spine surgery and the influence of spinal fusion procedures. Spine (Phila Pa 1976) 2007;32:382-7.

49. Dede O, Thuillier D, Pekmezci M, et al. Revision surgery for lumbar pseudarthrosis. Spine J 2015;15:977-82.

50. Adogwa O, Parker SL, Shau D, et al. Long-term outcomes of revision fusion for lumbar pseudarthrosis: clinical article. J Neurosurg Spine 2011;15:393-8.

51. Danielson BI, Frennered AK, Irstam LK. Radiologic progression of isthmic lumbar spondylolisthesis in young patients. Spine (Phila Pa 1976) 1991;16:422-5.

52. Labelle H, Roussouly P, Berthonnaud E, et al. Spondylolisthesis, pelvic incidence, and spinopelvic

Cite this article as: Zhan X, Xi X, Li F, Xiang Q, Qian J, $\mathrm{Yu} \mathrm{H}, \mathrm{He} \mathrm{L}, \mathrm{Yu} \mathrm{Y}$, Cheng L. Is reduction or arthrodesis in situ the optimal choice for adolescent spondylolisthesis?a systematic review and meta-analysis. Ann Palliat Med 2021;10(8):8523-8535. doi: 10.21037/apm-21-569 balance: a correlation study. Spine (Phila Pa 1976) 2004;29:2049-54.

53. Mac-Thiong JM, Labelle H. A proposal for a surgical classification of pediatric lumbosacral spondylolisthesis based on current literature. Eur Spine J 2006;15:1425-35.

54. Scaglietti O, Frontino G, Bartolozzi. Technique of anatomical reduction of lumbar spondylolisthesis and its surgical stabilization. Clin Orthop Relat Res 1976;(117):165-75.

55. Rombold C. Treatment of spondylolisthesis by posterolateral fusion, resection of the pars interarticularis, and prompt mobilization of the patient. An end-result study of seventy-three patients. J Bone Joint Surg Am 1966;48:1282-300.

56. Labelle H, Mac-Thiong JM, Roussouly P. Spinopelvic sagittal balance of spondylolisthesis: a review and classification. Eur Spine J 2011;20 Suppl 5:641-6.

57. Li Y, Hresko MT. Radiographic analysis of spondylolisthesis and sagittal spinopelvic deformity. J Am Acad Orthop Surg 2012;20:194-205.

58. DeWald RL, Faut MM, Taddonio RF, et al. Severe lumbosacral spondylolisthesis in adolescents and children. Reduction and staged circumferential fusion. J Bone Joint Surg Am 1981;63:619-26.

59. Gaines RW, Nichols WK. Treatment of spondyloptosis by two stage L5 vertebrectomy and reduction of L4 onto S1. Spine (Phila Pa 1976) 1985;10:680-6.

60. Wiltse LL, Jackson DW. Treatment of spondylolisthesis and spondylolysis in children. Clin Orthop Relat Res 1976;(117):92-100. 